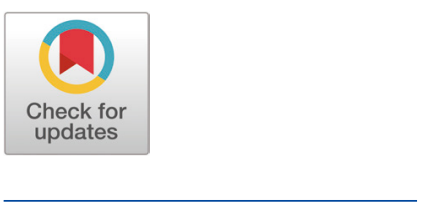

Received: May 21, 2020

Revised: May 26, 2020

Accepted: Jun 2, 2020

*Corresponding author Jung Min Heo

Department of Animal Science and Biotechnology, Chungnam National

University, Daejeon 34134, Korea.

Tel: +82-42-821-5777

E-mail: jmheo@cnu.ac.kr

Copyright $\odot 2020$ Korean Society of Animal Sciences and Technology.

This is an Open Access article distributed under the terms of the Creative Commons Attribution Non-Commercial License (http:// creativecommons.org/licenses/by$\mathrm{nc} / 4.0 /$ ) which permits unrestricted non-commercial use, distribution, and reproduction in any medium, provided the original work is properly cited.

ORCID

Eunjoo Kim

https://orcid.org/0000-0001-8884-6593 Samiru Sudharaka Wickramasuriya

https://orcid.org/0000-0002-6004-596X Taeg Kyun Shin

https://orcid.org/0000-0003-3587-8035 Hyun Min Cho

https://orcid.org/0000-0002-9329-8824

Hyeun Bum Kim

https://orcid.org/0000-0003-1366-6090

Jung Min Heo

https://orcid.org/0000-0002-3693-1320

Competing interests

The authors certify that there is no conflict of interest in the manuscript.

\section{Estimating total lysine requirement for optimised egg production of broiler breeder hens during the early-laying period}

\author{
Eunjoo Kim ${ }^{1,2}$, Samiru Sudharaka Wickramasuriya', Taeg Kyun Shin ${ }^{1}$, \\ Hyun Min Cho ${ }^{1}$, Hyeun Bum $\mathrm{Kim}^{3}$ and Jung Min $\mathrm{Heo}^{1 *}$
}

${ }^{1}$ Department of Animal Science and Biotechnology, Chungnam National University, Daejeon 34134, Korea ${ }^{2}$ School of Environmental and Rural Science, University of New England, Armidale, NSW 2351, Australia ${ }^{3}$ Department of Animal Resources Science, Dankook University, Cheonan 31116, Korea

\section{Abstract}

The production performance of broiler breeder hens in response to different levels of total lysine during the early laying period was investigated. A total of 126 Ross 308 parent stock hens were offered one of seven dietary treatments formulating elevated contents of total lysine ranging from $0.55 \%$ to $0.79 \%$ ( 0.04 scale; $133 \mathrm{~g}$ of feed) from 23 to 29 weeks of age. Each treatment had six replicates with three birds per pen. Body weight was recorded triweekly and eggs were collected and weighted at 9:00 am daily. One hen from each pen was euthanized to collect blood samples and visceral organs were harvested and weighed. Egg production, egg weight and egg mass were lower $(p<0.05)$ in hens offered a diet containing $0.55 \%$ total lysine compared to those fed the diet containing higher total lysine. Hens offered a diet containing $0.71 \%, 0.75 \%$, and $0.79 \%$ total lysine had greater $(p=0.008)$ egg production rate compared to those offered a diet containing lysine less than $0.71 \%$. The number of total eggs produced tended to be greater $(p=0.083)$ in hens offered a diet containing 0.71 and $0.75 \%$ total lysine compared to the other treatments. The number of settable egg production was higher $(p<0.001)$ in hens offered a diet contacting $0.79 \%$ total lysine compared to those fed the diet containing lower levels of total lysine. The relative weights of oviduct and ovary were lower $(p<0.05)$ in hens offered a diet containing $0.59 \%$ total lysine compared to the other treatments. No difference found in body weight, the number of total eggs, double-yolk eggs and abnormal shell eggs among the treatments. The urea nitrogen, estradiol-17 beta and progesterone in plasma were not affected by treatments. Based on linear- and quadratic-plateau models, total lysine requirements for egg production, settable egg production and egg mass at the early laying period were to be $0.73 \%, 0.77 \%$, and $0.71 \%$, respectively. Modern broiler breeder hens likely require higher total lysine than NRC recommendation in a diet for enhancing productivity during the early-laying period.

Keywords: Broiler breeders, Total lysine, Nutrient requirement, Linear- and quadratic-plateau models 
Funding sources

This work was financially supported by the research fund of Chungnam National University.

Acknowledgements

Not applicable.

Availability of data and material Upon reasonable request, the datasets of this study can be available from the corresponding author.

\section{Authors' contributions}

Conceptualization: Heo JM.

Data curation: Kim E.

Formal analysis: Kim E.

Methodology: Kim E, Wickramasuriya SS.

Software: Kim E.

Validation: Kim E, Heo JM.

Investigation: Kim E, Wickramasuriya SS, Shin TK, Cho HM.

Writing - original draft: Kim E, Heo JM.

Writing - review \& editing: Kim HB, Heo JM.

Ethics approval and consent to participate The experimental procedures were reviewed and approved by the Institutional Animal Care and Use Committee of the Chungnam National University, Daejeon, Korea (CNU00862).

\section{INTRODUCTION}

The genetic selection for faster growth rate along with improvements in the housing system and management has made a significant change in nutrient requirements of meat-type chickens [1]. It suggests that parent stock of meat-type chickens and broiler breeders should have undergone the same or similar changes of nutrient requirements similar to broiler chickens. Such improvement has generated the necessity of continuous evaluation of nutrient requirements in broiler breeders to enable them to perform satisfactorily. Nutrient Requirements of Poultry (NRC) [2] has been used for a standard reference of the poultry research over decades. The most recent version of NRC was published in 1994, but does not well describe amino acid requirements for broiler breeders at preand early-laying stages due to the insufficient research data.

It is common practice for broiler breeder hens being strictly controlled their daily feed allowance (50\%-60\% of ad libitum) to prevent obesity-related metabolic disorders and thereby to maintain their genetic capability of egg production. Fast-growing traits of broiler breeder hens are often negatively associated with egg-laying traits. For instance, reduced egg performance has been monitored in overfed hens with obesity-related liver and ovarian dysfunction [3-5]. As nutrition covers the large portion of entire management in broiler breeders, it is important to offer their nutrient requirements adequately in the limited allowance of daily rations. However, knowledge on nutrient requirements and responses including lysine of broiler breeders are high in scarcity.

Lysine has been used as the key reference for the accurate calculation of the ideal amino acids profile in non-ruminant animals [6-8]. In addition, lysine is the second-limiting amino acid in poultry rations when formulated a large proportion of corn and soybean meal. One important function of lysine is to increase body protein accretion, which would be an undesirable trait for broiler breeder hens due to higher sense of obesity in turn lower egg production rate $[9,10]$. In this regard, the correct amount of lysine in the diet would allow birds to use nutrients efficiently, by optimizing the balance of amino acids [11].

The objectives of the study were ( $\mathrm{i}$ ) to investigate responses to different total lysine levels on egg production, egg quality and organ and blood measurements of broiler breeder hens at early-laying period, and (ii) to evaluate the total lysine requirement based on the performance.

\section{MATERIALS AND METHODS}

The experimental procedures were reviewed and approved by the Animal Ethics Committee of the Chungnam National University (CNU-00862).

\section{Study design and experimental diets}

This experiment was conducted as a completely randomized design with seven treatments. The seven total lysine levels in the diet used in this experiment were $0.55 \%, 0.59 \%, 0.6 \% 3,0.6 \% 7,0.71 \%$, $0.75 \%$, and $0.79 \%$. Each treatment had six replicates with three hens per pen. Hens were randomly allotted in 42 pens and had a 2-week adjustment period to prevent the adverse effects on growth before the start of the study. All hens were fed the commercial pre-breeder diet with 2,800 ME $\mathrm{kcal} / \mathrm{kg}, 14.5 \% \mathrm{CP}$ and $2.1 \%$ calcium from 21 to 23 weeks of age. Hens were offered with the respective experimental diets from 23 to 29 weeks of age. A basal diet containing corn, wheat, and soybean meal was formulated to meet or exceed Ross 308 Parent Stock Nutrition Specifications, except for lysine (Table 1) [12]. 
Table 1. Composition (\%, as-is) of the experimental diets

\begin{tabular}{lccccccc}
\hline \multirow{2}{*}{ Total lysine (\%) } & \multicolumn{7}{c}{ Treatments } \\
\cline { 2 - 8 } & $\mathbf{0 . 5 5}$ & $\mathbf{0 . 5 9}$ & $\mathbf{0 . 6 3}$ & $\mathbf{0 . 6 7}$ & $\mathbf{0 . 7 1}$ & $\mathbf{0 . 7 5}$ & $\mathbf{0 . 7 9}$ \\
\hline Daily lysine intake (mg/d) & 732 & 785 & 838 & 891 & 944 & 997 & 1,050 \\
Corn & \multicolumn{1}{c}{ (1) } & - & 6.80 & 24.00 & 48.70 & 48.70 & 48.70 \\
Wheat & 67.88 & 67.88 & 60.88 & 38.36 & 11.16 & 10.16 & 10.10 \\
Wheat bran & 13.39 & 11.98 & 10.66 & 13.00 & 12.57 & 12.94 & 12.94 \\
Soybean meal & 7.36 & 9.20 & 10.70 & 13.47 & 16.40 & 17.00 & 17.00 \\
Vegetable oil & 1.93 & 1.50 & 1.50 & 2.00 & 2.00 & 2.00 & 2.00 \\
Limestone & 6.70 & 6.70 & 6.70 & 6.60 & 6.60 & 6.60 & 6.60 \\
Monocalcium phosphorous & 1.80 & 1.80 & 1.80 & 1.80 & 1.80 & 1.80 & 1.80 \\
Salt & 0.30 & 0.30 & 0.30 & 0.30 & 0.30 & 0.30 & 0.30 \\
Vitamin-mineral premix ${ }^{1)}$ & 0.30 & 0.30 & 0.30 & 0.30 & 0.30 & 0.30 & 0.30 \\
L-Lysine & - & - & 0.02 & - & - & 0.03 & 0.09 \\
DL-Methionine & 0.17 & 0.17 & 0.17 & 0.17 & 0.17 & 0.17 & 0.17 \\
L-Threonine & 0.17 & 0.17 & 0.17 & - & - & - & - \\
Calculated composition ${ }^{2)}$ & & & & & & & \\
ME (kcal/kg) & 2,800 & 2,800 & 2,800 & 2,805 & 2,807 & 2,800 & 2,800 \\
Crude protein (\%) & 15 & 15 & 15 & 15 & 15 & 15 & 15 \\
Calcium (\%) & 3.00 & 3.00 & 3.00 & 3.00 & 3.00 & 3.00 & 3.00 \\
Available P (\%) & 0.50 & 0.50 & 0.50 & 0.50 & 0.50 & 0.50 & 0.50 \\
Total lysine (\%) & 0.55 & 0.59 & 0.63 & 0.67 & 0.71 & 0.75 & 0.79 \\
\hline
\end{tabular}

${ }^{11}$ Vitamin-mineral premix provided following nutrients (per kg of air-dry diet): Vitamins: A 12,000 IU, D 33,000 IU, E $15 \mathrm{mg}, \mathrm{K}$ $2 \mathrm{mg}$, thiamine $2 \mathrm{mg}$, riboflavin $6 \mathrm{mg}$, pyridoxine $2 \mathrm{mg}$, calcium pantothenate $0.03 \mathrm{mg}$, folic acid $0.2 \mathrm{mg}$, niacin $45 \mathrm{mg}$, biotin $0.15 \mu$ g. Minerals: calcium $0.5 \%$, Co $0.5 \mathrm{mg}$ (as cobalt sulphate), Cu $10 \mathrm{mg}$ (as copper sulphate), iodine $0.9 \mathrm{mg}$ (as potassium iodine), iron $80 \mathrm{mg}$ (as ferrous sulphate), $\mathrm{Mn} 80 \mathrm{mg}$ (as manganous oxide), Se $0.2 \mathrm{mg}$ (as sodium selenite), Zn $80 \mathrm{mg}$ (as zinc oxide).

${ }^{2)}$ The values are calculated according to the values of feedstuffs in NRC [2].

$\mathrm{ME}$, metabolizable energy.

\section{Birds and husbandry}

A total of 126 21-week old Ross 308 broiler breeder pullets in similar body weight $(2,188 \pm 32 \mathrm{~g})$ were selected from a commercial flock. Upon arrival, birds were kept in a controlled environment poultry house at $22 \pm 2^{\circ} \mathrm{C}$ under a lighting program in 8 hours light: 16 hours dark. Birds were photo-stimulated with 12 hours light at 22 weeks of age (40 Lux) and the light was gradually increased by 1 hour per week to a photoperiod of 14 hours light: 10 hours dark until 25 weeks of age. This was maintained until the end of the study at 29 weeks of age. All birds were offered the same daily feed allocation by once-a-day feeding (average $133 \mathrm{~g}$ per hen per day). The Ross 308 Parent Stock Manual [13] was used as a reference for restricted feeding and all management. Water was available ad libitum. All treatment groups were equally restricted to the amount of feed throughout the experimental period.

\section{Data collection}

Broiler breeder hens were weighed on a pen basis at 23, 26, and 29 weeks of age. All eggs per pen were collected at 9 am daily, weighed, and then hen-day egg production was calculated. Average egg weight and egg mass per week were calculated. The number of settable eggs ( $\geq 50 \mathrm{~g}$ ) and double-yolk and abnormal shell eggs were recorded. 


\section{Post-mortem procedures and organ measurements}

At 29 weeks of age, one bird pen was randomly selected, weighed and euthanized by cervical dislocation. The oviduct and ovary were removed from the body and weighed. The number of large yellow follicles (> $10 \mathrm{~mm}$ diameter), small yellow follicles (5 to $10 \mathrm{~mm}$ diameter), and large white follicle (3 to $5 \mathrm{~mm}$ diameter) were recorded as described by [14]. Oviduct and ovary weights were expressed as a percentage of live body weight.

\section{Plasma urea nitrogen and serum hormone analysis}

Blood samples were collected from the brachial vein of each hen at 29 weeks of age using EDTA-coated vacuum blood collection tubes and non-heparinised tubes. The blood was centrifuged at 3,000 rpm for 15 minutes at $4{ }^{\circ} \mathrm{C}$ and stored at $-80{ }^{\circ} \mathrm{C}$ until plasma urea nitrogen and serum hormones were quantified. Plasma urea nitrogen levels were analyzed by Enzymatic assay method using Automatic Analyser 7180 (Hitachi, Japan). Estradiol-17 $\beta$ and progesterone in serum were quantified using a Cobas ${ }^{\circledR} 6000$ (e601 module) analyser (Roche, Mannheim, Germany) with electrochemiluminescent immunoassay kits.

\section{Statistical analysis}

The data from this experiment were analyzed as a completely randomized design by one-way ANOVA using the General Linear Model procedure of SPSS statistics 22 (IBM SPSS, Chicago, IL, USA). All the data was tested for the normal distribution using Kolmogorov-Smirnova test. Levene's homogeneity of variance test was used, and Welch's ANOVA was used when unequal variances were found. Tukey's HSD test was used to separate the means when significant effects were detected at the $5 \%$ levels $(p<0.05)$. To determine the total lysine requirement, linear-plateau and quadratic-plateau regression analysis were conducted using a Nutritional Response Model (Version 1.1) [15].

\section{RESULTS}

No mortality was found throughout the study. Body weight was not affected by different total lysine levels at 23, 26, and 29 weeks of age (Table 2).

\section{Egg production}

Overall egg production, egg weight and egg mass from 23 to 29 weeks of age are presented in Table 3. The egg production rate was lower $(p=0.008)$ in hens offered the diet containing $0.55 \%$ total

Table 2. Body weight ( $g / h e n$ ) of broiler breeders fed different levels of lysine from 23 to 29 week of age

\begin{tabular}{|c|c|c|c|c|}
\hline Total lysine (\%) & Daily lysine intake (mg/d) & 23 week of age & 26 week of age & 29 week of age \\
\hline 0.55 & 735 & 2,785 & 3,197 & 3,499 \\
\hline 0.59 & 785 & 2,775 & 3,106 & 3,360 \\
\hline 0.63 & 838 & 2,837 & 3,155 & 3,519 \\
\hline 0.67 & 891 & 2,811 & 3,149 & 3,439 \\
\hline 0.71 & 944 & 2,779 & 3,114 & 3,472 \\
\hline 0.75 & 998 & 2,817 & 3,111 & 3,364 \\
\hline 0.79 & 1,051 & 2,862 & 3,181 & 3,518 \\
\hline \multicolumn{2}{|c|}{ SEM } & 27.1 & 12.8 & 27.1 \\
\hline \multicolumn{2}{|c|}{$p$-value } & 0.981 & 0.350 & 0.515 \\
\hline
\end{tabular}

SEM, standard error of the mean. 
Table 3. Hen-day egg production of broiler breeder hens fed graded levels of total lysine from 23 to 29 week of age ${ }^{1)}$

\begin{tabular}{|c|c|c|c|c|}
\hline Total lysine (\%) & Daily lysine intake (mg/d) & Overall egg production (\%) & Egg weight (g) & Egg mass $(g / d)$ \\
\hline 0.55 & 732 & $31.4^{a}$ & $49.6^{a}$ & $16.54^{\mathrm{a}}$ \\
\hline 0.59 & 785 & $34.6^{\mathrm{ab}}$ & $50.7^{\mathrm{ab}}$ & $19.11^{b}$ \\
\hline 0.63 & 838 & $37.2^{\mathrm{ab}}$ & $51.8^{\mathrm{bc}}$ & $20.61^{b}$ \\
\hline 0.67 & 891 & $37.3^{\mathrm{ab}}$ & $53.2^{\mathrm{c}}$ & $22.24^{\mathrm{b}}$ \\
\hline 0.71 & 944 & $41.7^{\mathrm{b}}$ & $51.6^{\mathrm{bc}}$ & $24.60^{c}$ \\
\hline 0.75 & 998 & $41.0^{b}$ & $51.2^{b}$ & $23.26^{b c}$ \\
\hline 0.79 & 1,051 & $38.6^{\mathrm{ab}}$ & $53.3^{\mathrm{c}}$ & $22.34^{\mathrm{b}}$ \\
\hline \multicolumn{2}{|c|}{ SEM } & 1.01 & 0.28 & 1.11 \\
\hline \multicolumn{2}{|c|}{$p$-value } & 0.008 & 0.001 & 0.009 \\
\hline
\end{tabular}

${ }^{1}$ Results are the mean of 6 replicates per treatment.

${ }^{a-c}$ Means within the same column with no common script differ significantly $(p<0.05)$.

SEM, standard error of the mean.

lysine compared to other treatments, and hens offered the diet containing $0.71 \%, 0.75 \%$, and $0.79 \%$ total lysine showed greater egg production rate compared to those offered the diet containing $0.59 \%$, $0.63 \%$, and $0.67 \%$ total lysine.

The number of settable and defective eggs are shown in Table 4. The number of settable egg produced was lower $(p<0.001)$ in hens offered the diet containing $0.55 \%$ and $0.59 \%$ total lysine diet compared with those offered the diet containing $0.67 \%, 0.75 \%$, and $0.79 \%$ total lysine. The number of double yolk egg and abnormal shell eggs were not affected by total lysine concentrations in the diets.

\section{Estimation of lysine requirement}

Estimated total lysine requirements are presented in Table 5. The total lysine requirements for egg production rate, the number of settable egg production and egg mass were estimated to be $0.68 \%$, $0.67 \%$ and $0.69 \%$ of the diets, respectively, based on the linear-plateau regression model. When the data were fitted to the quadratic-plateau regression model, the total lysine requirements for egg production rate, settable egg production and egg mass were estimated to be $0.78 \%, 0.87 \%$, and $0.73 \%$ of the diets, respectively. By combining values from the two models, the recommended total lysine

Table 4. Number of defective egg produced ( $\mathrm{n} / \mathrm{hen}$ ) from 23 to 29 week of age affected by different levels of total lysine in broiler breeder hens ${ }^{1)}$

\begin{tabular}{|c|c|c|c|c|c|}
\hline Total lysine (\%) & Daily lysine intake (mg/d) & Total eggs produced & Settable eggs ${ }^{2)}$ & Double-yolk eggs & Abnormal shell eggs ${ }^{3)}$ \\
\hline 0.55 & 732 & 42.3 & $23.7^{\mathrm{a}}$ & 0.5 & 0.7 \\
\hline 0.59 & 785 & 46.7 & $25.3^{\mathrm{ab}}$ & 0.5 & 0.5 \\
\hline 0.67 & 891 & 50.5 & $39.8^{\mathrm{cd}}$ & 0.8 & 0.0 \\
\hline 0.71 & 944 & 56.3 & $35.3^{\mathrm{cd}}$ & 0.2 & 1.0 \\
\hline \multicolumn{2}{|c|}{ SEM } & 2.54 & 1.48 & 0.14 & 0.11 \\
\hline \multicolumn{2}{|c|}{$p$-value } & 0.083 & $<0.001$ & 0.447 & 0.333 \\
\hline
\end{tabular}

\footnotetext{
${ }^{1)}$ Results are the mean $(n=3)$ of 6 replicates per treatment.

${ }^{2}$ Settable eggs $(n /$ hen $)=$ normal egg $\geq 50 \mathrm{~g}$.

${ }^{3)}$ Abnormal shell eggs $(\mathrm{n} / \mathrm{hen})=$ soft shell, shell-less and cracked eggs.

${ }^{a-d}$ Means within the same column with no common script differ significantly $(p<0.05)$.

SEM, standard error of the mean.
} 
Table 5. Estimated dietary total lysine requirements and recommendations for broiler breeder hens from 23 to 29 weeks of age based on linearplateau and quadratic-plateau regression analysis

\begin{tabular}{|c|c|c|c|c|c|}
\hline Item & Requirement (\%) & SE & $R^{2}(\%)$ & $p$-value & Recommendation (\%) \\
\hline \multicolumn{6}{|c|}{ Egg production rate } \\
\hline LP & 0.68 & 0.035 & 77.76 & $<0.001$ & 0.73 \\
\hline QP & 0.78 & 0.118 & 76.26 & 0.003 & \\
\hline \multicolumn{6}{|c|}{ Settable egg production } \\
\hline LP & 0.67 & 0.055 & 74.85 & $<0.001$ & 0.77 \\
\hline $\mathrm{QP}$ & 0.87 & 0.370 & 72.28 & $<0.001$ & \\
\hline \multicolumn{6}{|l|}{ Egg mass } \\
\hline LP & 0.69 & 0.022 & 93.56 & 0.001 & 0.71 \\
\hline QP & 0.73 & 0.045 & 92.76 & 0.001 & \\
\hline
\end{tabular}

SE, standard error; LP, linear-plateau regression analysis; QP, quadratic-plateau regression analysis.

requirement was estimated to be $0.73 \%, 0.77 \%$, and $0.71 \%$ of the diet for optimal egg production, the number of settable eggs and egg mass, respectively.

\section{Organ measurements}

Absolute and relative weights of reproductive organs are presented in Table 6. Oviduct and ovary weights at 29 weeks of age are presented in Table 6 . Hens offered the diet containing $0.59 \%$ and $63 \%$ total lysine had lower $(p=0.002)$ absolute oviduct weights compared to those offered the diet containing $0.75 \%$ total lysine. Similarly, hens offered the diet containing $0.59 \%$ total lysine had a lower $(p=0.029)$ relative oviduct weight compared to those offered the diet containing total lysine more than $0.63 \%$. Absolute and relative ovary weights were lower $(p=0.001$ and $p=0.003$, respectively) in hens offered the diet containing $0.59 \%$ total lysine relative to hens offered the diet containing $0.55 \%, 0.63 \%, 0.67 \%, 0.71 \%, 0.75 \%$, and $0.79 \%$ total lysine.

Ovarian follicle numbers of broiler breeder hens are presented in Table 7 . The number of large yellow follicles were the lowest $(p=0.016)$ in hen fed the diet containing $0.59 \%$ total lysine among the treatments. Continuously, hens offered the diet containing $0.55 \%$ and $0.59 \%$ total lysine showed the lower $(p=0.002)$ number of small yellow follicles compared to those fed the diet containing

Table 6. Oviduct and ovary weights of broiler breeder hens fed gradient levels of lysine at 29 weeks of age ${ }^{1)}$

\begin{tabular}{|c|c|c|c|c|c|}
\hline \multirow{2}{*}{ Total lysine (\%) } & \multirow{2}{*}{ Lysine intake $(\mathrm{mg} / \mathrm{d})$} & \multicolumn{2}{|c|}{ Oviduct } & \multicolumn{2}{|c|}{ Ovary } \\
\hline & & g & $\%^{2)}$ & g & $\%$ \\
\hline 0.55 & 732 & $63.92^{b c}$ & $1.77^{\mathrm{ab}}$ & $56.07^{b}$ & $1.24^{a}$ \\
\hline 0.59 & 785 & $45.85^{\mathrm{a}}$ & $1.43^{\mathrm{a}}$ & $33.43^{\mathrm{a}}$ & $1.05^{\mathrm{a}}$ \\
\hline 0.63 & 838 & $61.02^{b}$ & $1.83^{b}$ & $62.83^{b}$ & $1.89^{b}$ \\
\hline 0.67 & 891 & $64.72^{\mathrm{bc}}$ & $1.84^{\mathrm{b}}$ & $58.90^{b}$ & $1.68^{b}$ \\
\hline 0.71 & 944 & $71.27^{\mathrm{bc}}$ & $2.01^{b}$ & $62.33^{b}$ & $1.75^{b}$ \\
\hline 0.75 & 998 & $73.50^{c}$ & $2.15^{\mathrm{b}}$ & $59.48^{\mathrm{b}}$ & $1.74^{b}$ \\
\hline 0.79 & 1,051 & $64.98^{\mathrm{bc}}$ & $1.94^{\mathrm{b}}$ & $55.33^{b}$ & $1.66^{b}$ \\
\hline \multicolumn{2}{|c|}{ SEM } & 1.736 & 0.053 & 2.091 & 0.061 \\
\hline \multicolumn{2}{|c|}{$p$-value } & 0.002 & 0.029 & $<0.001$ & 0.003 \\
\hline
\end{tabular}

\footnotetext{
${ }^{1)}$ Results are the mean of 6 replicates per treatment.

${ }^{2)} \%$ = organ weight $/$ body weight $\times 100$.

${ }^{a-c}$ Means within the same column with no common script differ significantly $(p<0.05)$.

SEM, standard error of the mean.
} 
Table 7. Ovarian follicle numbers ( $\mathrm{n} / \mathrm{hen}$ ) of broiler breeder hens fed gradient lysine levels at 29 weeks of age ${ }^{1)}$

\begin{tabular}{ccccc}
\hline Total lysine (\%) & Lysine intake $(\mathbf{m g} / \mathbf{d})$ & Large yellow follicles & Small yellow follicles & Large white follicles \\
\hline 0.55 & 732 & $5.5^{\mathrm{b}}$ & $2.3^{\mathrm{a}}$ & 19.2 \\
0.59 & 785 & $3.5^{\mathrm{a}}$ & $2.8^{\mathrm{a}}$ & 16.8 \\
0.63 & 838 & $5.7^{\mathrm{b}}$ & $5.8^{\mathrm{ab}}$ & 22.5 \\
0.67 & 891 & $5.3^{\mathrm{b}}$ & $8.0^{\mathrm{bc}}$ & 18.5 \\
0.71 & 944 & $6.2^{\mathrm{b}}$ & $8.8^{\mathrm{bc}}$ & 19.5 \\
0.75 & 998 & $5.7^{\mathrm{b}}$ & $13.5^{\mathrm{c}}$ & 15.8 \\
0.79 & 1,051 & $6.0^{\mathrm{b}}$ & $11.7^{\mathrm{c}}$ & 15.3 \\
\hline & & 0.174 & 0.888 & 0.689 \\
& SEM & & 0.016 & 0.002 \\
\hline
\end{tabular}

${ }^{11}$ Results are the mean of 6 replicates per treatment.

${ }^{a-c}$ Means within the same column with no common script differ significantly $(p<0.05)$.

Large yellow follicles (> $10 \mathrm{~mm}$ diameter); small yellow follicles (5 to $10 \mathrm{~mm}$ diameter); large white follicles ( 3 to $5 \mathrm{~mm}$ diameter); SEM, standard error of the mean.

$0.71 \%, 0.75 \%$, and $0.79 \%$ total lysine.

\section{Blood measurements}

Plasma metabolite and serum hormone levels are presented in Table 8. Gradient total lysine levels in the diets did not affect plasma urea nitrogen concentration $(p=0.114)$ as well as serum estradiol-17 $\beta$ and progesterone concentrations ( $p=0.192$ and $p=0.607$, respectively) on 29 weeks of age in broiler breeder hens.

\section{DISCUSSION}

The metabolic pathway of lysine has been altered from muscle tissue to egg formation once broiler breeders commence their egg production, and the amount of lysine partitioned to egg formation changes according to the egg production rate [16]. In this regard, dietary lysine intake should be shortly adjusted as per hens' age and stage of egg production, however no sufficient data on the responses to various levels of lysine in broiler breeder hens in an early-laying stage are available. Therefore, this study aimed to investigate the performance of broiler breeder hens in response to different total lysine levels and establish lysine requirements with regards to the observations ac-

Table 8. Plasma urea nitrogen concentration, serum estradiol-17 $\beta$ concentration and serum progesterone concentrations at 29 week of age in broiler breeder hens fed gradient lysine levels ${ }^{1)}$

\begin{tabular}{|c|c|c|c|c|}
\hline Total lysine (\%) & Daily lysine intake (mg/d) & Plasma urea nitrogen (mg/dL) & Serum P4 (ng/mL) & Serum E2 (pg/mL) \\
\hline 0.55 & 732 & 0.32 & 0.26 & 330.6 \\
\hline 0.59 & 785 & 0.44 & 0.09 & 347.8 \\
\hline 0.63 & 838 & 0.33 & 0.38 & 345.7 \\
\hline 0.67 & 891 & 0.38 & 0.14 & 389.9 \\
\hline 0.71 & 944 & 0.51 & 0.81 & 433.6 \\
\hline 0.75 & 998 & 0.46 & 0.08 & 405.1 \\
\hline 0.79 & 1,051 & 0.47 & 0.17 & 353.4 \\
\hline \multicolumn{2}{|c|}{ SEM } & 0.022 & 0.063 & 16.08 \\
\hline \multicolumn{2}{|c|}{$p$-value } & 0.114 & 0.192 & 0.607 \\
\hline
\end{tabular}

${ }^{11}$ Results are the mean of 6 replicates per treatment.

$\mathrm{P} 4$, progesterone; $\mathrm{E} 2$, estradiol-17 $\beta$; SEM, standard error of the mean. 
quired.

To eliminate a possibility of inaccurate estimation of the requirement using multiple range tests, in the present study, linear-plateau and quadratic-plateau regression analyses were used to determine the total lysine requirement [15]. Hence, the present study adopted a combined approach suggested by Nørgaard et al. [17] to overcome the variations in requirements within intra-statistical methods such as over- and under-estimation of the value. The nutrient requirement refers to the nutrient concentration of feed that maximize profits, and thus egg production rate, the number of produced settable eggs and egg mass were used as output for the estimation. Our findings suggested that $0.73 \%, 0.77 \%$, and $0.71 \%$ total lysine in diets to optimize egg production rate, settable egg production and egg mass, respectively, and this value is corresponded to $971,1,024$ and $944 \mathrm{mg} /$ hen/day, respectively. Our estimations are greater than NRC [2] recommendation, $765 \mathrm{mg} /$ hen/day, suggesting that genetic improvements of broiler breeder hens have made a considerable difference in nutritional needs. Our results are supported by Fakhraei et al. [18] where $979 \mathrm{mg} / \mathrm{hen} / \mathrm{day}$ of total lysine requirement for egg production, egg mass and egg content was calculated using the broken-line model in 52-week-old Arian broiler breeder hens.

In the present study, different lysine levels in the diets did not influence on hens' body weight, but altered egg-laying performance. Joseph et al. [19] found that Cobb 500 broiler breeders from 20 to 29 weeks of age had no difference in body weight while egg weights and egg production rate in responses to crude protein level in the diets were observed. Mohiti-Asli et al. [4] revealed that the body weight gain of matured hens might be more susceptible to energy intake rather than crude protein consumption. Further, the diets tested in the present study were iso-calorically formulated with $15 \%$ of fixed crude protein contents and thus, no difference in body weights regarding the different lysine contents. Thus, it is reasonable to postulate differences in total lysine contents would have a minor impact on body weight during the early laying period.

Our findings demonstrated that hens offered the diet containing $0.55 \%$ lysine had lower relative oviduct and ovary weights accompanying decreased egg production. This is likely because $0.55 \%$ of total lysine in the diet might not be adequate to fully develop the reproductive organs in the early-laying phase. It has been suggested by Bruggeman et al. [20] that the proportional weights of ovary and oviduct should be above $1.70 \%$ and $1.58 \%$, respectively, at the first egg-laying for future consistent reproductive performance. In the present study, hens offered the diet containing $0.55 \%$ total lysine had morphologically immature ovaries as ovary and oviduct of those hens accounted for only $1.43 \%$ and $1.05 \%$ of live body weights, respectively. It is speculated that feeding hens the diet with $0.55 \%$ and $0.59 \%$ lysine during the early-laying period have detrimental nutritional consequences resulted from imbalance amino acid in the diet and thus insufficient growth of the reproductive organ.

Quantification of urea nitrogen in blood has been used as an indirect tool to evaluate the protein utilisation in non-ruminant animals [21-23]. In the present study, the concentration of plasma urea nitrogen in response to different lysine levels was investigated to see if excessive or deficient lysine in the diet influences the amino acid utilisation. However, no difference in plasma urea nitrogen affected by graded lysine levels can be partially explained by research done by Donsbough et al. [22] who demonstrated that blood urea nitrogen levels were easily altered by feeding regimen and blood collection time. Excessive uric acid entered into the caeca can break down to ammonia and carbon dioxide by bacterial activity and this ammonia is known to be rapidly absorbed for amino acid synthesis by birds [24]. In the present study, blood samples were selectively collected from birds commenced laying only once at 29 weeks of age and the sample birds successfully achieved the normal body weight without obesity by the time. Thus, it is speculated that the quantification of plasma urea nitrogen was not suitable to assess the ability of nitrogen utilisation of matured hens at the 
normal laying period.

Egg formation including differentiation of ovarian follicles is under the control of reproductive hormones such as estradiol-17 $\beta$ and progesterone $[25,26]$. However, in the present study, different lysine levels altered hen-day egg production rate, while serum estradiol-17 $\beta$ and progesterone concentrations at 29 weeks of age were not influenced by the lysine levels. According to the breeder guideline, 29 weeks of age is a start of peak-production for broiler breeders and all hens tested in the present study reached the egg production rate of more than $70 \%$ at 29 weeks of age, irrespective of dietary total lysine levels. Onagbesan et al. [27] reported that levels of plasma hormones such as progesterone and estradiol-17 $\beta$ s were not correlated to egg production rate however likely to be age-related in broiler breeders. Thus, our findings confirmed that there was no clear relationship between egg production rate and blood reproductive hormone levels once hens were in the stable period of egg laying. Further research is needed to determine the age-related changes in reproductive hormone levels along with nutritional factors in broiler breeder hens.

The delay in ovulation due to the apoptosis and necrosis within the ovarian follicles has been observed in egg-type chickens with reduced egg production rate [28]. Thus, the reduction in a number of small yellow follicles may be symptomatic of an inadequate ability to support optimal rates of ongoing egg production [29]. However, the link between a single nutrient (i.e., dietary lysine) and ovarian morphology has not been explored. The current results showed that different total lysine levels altered the number of large and small yellow follicles, and the sum total yellow follicles were less than 10 in hens offered the diet containing $0.55 \%$ and $0.59 \%$ total lysine, supporting their lower egg production rate and decreased total egg mass compared with hens fed the diet containing more than $0.63 \%$ lysine. It is reasonable to assume that a relatively reduced egg production in hens offered the diet containing $0.55 \%$ and $0.59 \%$ total lysine might be partially due to decreased follicular recruitment into the F1 yolk follicle pool, evidenced by Robinson et al. [30] where an increased atresia of small yellow follicles was observed when hens were unable to appropriately manage the ovarian follicles in the hierarchy. One reason for this could be due to the dietary lysine partitioning between maintenance and production was likely to be disturbed when dietary lysine was not adequate, suggested by Ekmay et al. [16] found that lysine used for primarily towards muscle, and then excessive lysine utilized to egg production when needed in broiler breeder hens during the early laying period.

In the present study, the production of defective eggs along with the morphology of ovarian follicles was monitored to determine if the different lysine levels in the diet could be a factor of egg production in broiler breeder hens. There was a trend in the number of total egg produced $(n / h e n)$ throughout the study, and hens fed the diet containing $0.71 \%$ lysine contents increased number of total produced eggs by 14 compared with birds offered the diet containing $0.55 \%$ total lysine. In addition, approximately $56 \%$ of total eggs produced by hens offered the diet containing $0.55 \%$ lysine were settable ( $>50 \mathrm{~g}$ of egg weights). This indicates that lower lysine intake might negatively affect the production of total or settable eggs and possibly hatchability, considering that the $85 \%$ of total eggs produced by hens offered $0.79 \%$ lysine were settable. Other poor egg quality features such as double-yolk and abnormal shell were not affected by dietary treatments, suggesting that different total lysine levels did not contribute to hyperovulation and eggshell qualities. Egg formation is the outcome of highly merged and a very tightly scheduled multi-tissue processes. The whole process of egg formation has a very tiny biological tolerance for excess and/or deficiency, so the oviposition for settable egg production has easily been disturbed by nutritional and environmental factors $[19,29,31-33]$. Thus, our findings indicated that $0.55 \%$ of total lysine would be deficient for broiler breeder hens and could possibly have detrimental impacts on the egg quality as well as reproductive performance during the early-laying period. The diet containing $0.79 \%$ total lysine, the highest 
lysine level tested in the present study, was not associated with obesity, double-hierarchy of large yellow follicles and abnormal shell production, suggesting it would be applicable to increase dietary lysine level of hens' diet to optimize the performance when the crude protein level is not extreme.

\section{CONCLUSION}

In conclusion, different levels of total lysine do not appear to be a major contributor to body weight, defective egg quality and blood hormone concentrations. However, $0.55 \%$ and $0.59 \%$ total lysine of hens' diet appears to have a potential risk as a consequence of decreasing the number of ovarian follicles and immature reproductive organs, which in turn cause the reduced settable egg production. On the other hand, hens offered the diet containing total lysine more than $0.63 \%$ showed stable egg production that was mostly settable, and adequately developed ovarian follicle morphology together with the well-developed oviduct. Based on linear- and quadratic-plateau models, total lysine requirement for egg production, settable egg production and egg mass at the early laying period would be $0.73 \%, 0.77 \%$, and $0.71 \%$, respectively. Our findings clearly demonstrated that broiler breeder's production performance could be improved by a certain level of total lysine in the diet. Further research is warranted to establish the ideal amino acid profile according to the optimum lysine level as a reference for broiler breeder hens.

\section{REFERENCES}

1. Havenstein GB, Ferket PR, Qureshi MA. Growth, livability, and feed conversion of 1957 versus 2001 broilers when fed representative 1957 and 2001 broiler diets. Poult Sci. 2003;82:15008.

2. NRC [National Research Council]. Nutrient requirements of poultry: 1994. Washington, DC: National Academies Press; 1994.

3. Walzem RL, Chen S. Obesity-induced dysfunctions in female reproduction: lessons from birds and mammals. Adv Nutr. 2014;5:199-206.

4. Mohiti-Asli M, Shivazad M, Zaghari M, Rezaian M, Aminzadeh S, Mateos GG. Effects of feeding regimen, fiber inclusion, and crude protein content of the diet on performance and egg quality and hatchability of eggs of broiler breeder hens. Poult Sci. 2012;91:3097-106.

5. Chen SE, McMurtry JP, Walzem RL. Overfeeding-induced ovarian dysfunction in broiler breeder hens is associated with lipotoxicity. Poult Sci. 2006;85:70-81.

6. Baker DH, Han Y. Ideal amino acid profile for chicks during the first three weeks posthatching. Poult Sci. 1994;73:1441-7.

7. Boisen S. Ideal dietary amino acid profiles for pigs. In: D’Mello JPF, editor. Amino acids in animal nutrition. Oxon: CABI Publisher; 2003. p. 157-68.

8. Mack S, Bercovici D, De Groote G, Leclercq B, Lippens M, Pack M, et al. Ideal amino acid profile and dietary lysine specification for broiler chickens of 20 to 40 days of age. Br Poult Sci. 1999;40:257-65.

9. Tesseraud S, Peresson R, Lopes J, Chagneau AM. Dietary lysine deficiency greatly affects muscle and liver protein turnover in growing chickens. Br J Nutr. 1996;75:853-65.

10. Tesseraud S, Temim S, Le Bihan-Duval E, Chagneau AM. Increased responsiveness to dietary lysine deficiency of pectoralis major muscle protein turnover in broilers selected on breast development. J Anim Sci. 2001;79:927-33.

11. Wecke $\mathrm{C}$, Pastor $\mathrm{A}$, Liebert F. Validation of the lysine requirement as reference amino acid for ideal in-feed amino acid ratios in modern fast growing meat-type chickens. Open J Anim Sci. 
2016;6:185-94.

12. Aviagen. Ross 308 parent stock: nutrients specification. Huntsville, AL: Aviagen; 2014.

13. Aviagen. Ross 308 parent stock: management guidelines. Huntsville, AL: Aviagen; 2016.

14. Robinson FE, Etches RJ. Ovarian steroidogenesis during foillicular maturation in the domestic fowl (Gallus domesticus). Biol Reprod. 1986;35:1096-105.

15. Vedenov D, Pesti GM. A comparison of methods of fitting several models to nutritional response data.J Anim Sci. 2008;86:500-7.

16. Ekmay RD, Salas C, England J, Cerrate S, Coon CN. Lysine partitioning in broiler breeders is not affected by energy or protein intake when fed at current industry levels. Poult Sci. 2014;93:1737-44.

17. Nørgaard JV, Pedersen TF, Soumeh EA, Blaabjerg K, Canibe N, Jensen BB, et al. Optimum standardized ileal digestible tryptophan to lysine ratio for pigs weighing 7-14 kg. Livest Sci. 2015;175:90-5.

18. Fakhraei J, Loutfollahian H, Shivazad M, Chamani M, Hoseini S. Reevaluation of lysine requirement based on performance responses in broiler breeder hens. Afr J Agric Res. 2010;5:2137-42.

19. Joseph NS, Robinson FE, Korver DR, Renema RA. Effect of dietary protein intake during the pullet-to-breeder transition period on early egg weight and production in broiler breeders. Poult Sci. 2000;79:1790-6.

20. Bruggeman V, Onagbesan O, D'Hondt E, Buys N, Safi M, Vanmontfort D, et al. Effects of timing and duration of feed restriction during rearing on reproductive characteristics in broiler breeder females. Poult Sci. 1999;78:1424-34.

21. Coma J, Carrion D, Zimmerman D. Use of plasma urea nitrogen as a rapid response criterion to determine the lysine requirement of pigs.J Anim Sci. 1995;73:472-81.

22. Donsbough AL, Powell S, Waguespack A, Bidner TD, Southern LL. Uric acid, urea, and ammonia concentrations in serum and uric acid concentration in excreta as indicators of amino acid utilization in diets for broilers. Poult Sci. 2010;89:287-94.

23. Kohn RA, Dinneen MM, Russek-Cohen E. Using blood urea nitrogen to predict nitrogen excretion and efficiency of nitrogen utilization in cattle, sheep, goats, horses, pigs, and rats. J Anim Sci. 2005;83:879-89.

24. Karasawa $Y$, Kawai H, Hosono A. Ammonia production from amino acids and urea in the caecal contents of the chicken. Comp Biochem Physiol B. 1988;90:205-7.

25. Laguë PC, Van Tienhoven A, Cunningham FJ. Concentrations of estrogens, progesterone and LH during the ovulatory cycle of the laying chicken (Gallus domesticus). Biol Reprod. 1975;12:590-8.

26. Sockman KW, Schwabl H. Daily estradiol and progesterone levels relative to laying and onset of incubation in canaries. Gen Comp Endocrinol. 1999;114:257-68.

27. Onagbesan OM, Metayer S, Tona K, Williams J, Decuypere E, Bruggeman V. Effects of genotype and feed allowance on plasma luteinizing hormones, follicle-stimulating hormones, progesterone, estradiol levels, follicle differentiation, and egg production rates of broiler breeder hens. Poult Sci. 2006;85:1245-58.

28. Williams JB, Sharp PJ. Ovarian morphology and rates of ovarian follicular development in laying broiler breeders and commercial egg-producing hens. Br Poult Sci. 1978;19:387-95.

29. Hocking PM, Bernard R, Robertson GW. Effects of low dietary protein and different allocations of food during rearing and restricted feeding after peak rate of lay on egg production, fertility and hatchability in female broiler breeders. Br Poult Sci. 2002;43:94-103.

30. Robinson FE, Wilson JL, Yu MW, Fasenko GM, Hardin RT. The relationship between body 
weight and reproductive efficiency in meat-type chickens. Poult Sci. 1993;72:912-22.

31. Chaney LW, Fuller HL. The relation of obesity to egg production in broiler breeders. Poult Sci. 1975;54:200-8.

32. Yu MW, Robinson FE, Charles RG, Weingardt R. Effect of feed allowance during rearing and breeding on female broiler breeders.: 2. ovarian morphology and production. Poult Sci. 1992;71:1750-61.

33. Renema RA, Robinson FE, Goerzen PR, Zuidhof MJ. Effects of altering growth curve and age at photostimulation in female broiler breeders. 2. egg production parameters. Can J Anim Sci. 2001;81:477-86. 